\title{
CALIBRATION OF THE FRACTURE LOCUS OF AN AlSi10 ALUMINUM ALLOY
}

\author{
LORENZO FRACCAROLI, MARCO NICOLA MASTRONE \& FRANCO CONCLI \\ Free University of Bolzano/Bozen, Faculty of Science and Technology, Italy
}

\begin{abstract}
The aim of this paper is to calibrate the fracture locus (FL) of an aluminum alloy. The approach used is based on an iterative procedure that involves finite element (FE) simulations and experimental tests. Unidirectional tensile tests on three specimens having different notches were performed to induce different states of stress inside the material. The constitutive law was calibrated using the Voce equation. Experiments were reproduced with FE simulations to extract parameters like equivalent plastic strain at fracture, triaxiality and Lode parameter, successively used for tuning the fracture locus of the considered material.
\end{abstract}

Keywords: FEM, ductile damage models, fracture locus, Rice and Tracey, AlSilo.

\section{INTRODUCTION}

Aluminum alloys are widely used in various engineering fields, e.g. aerospace, automotive and railway sectors. They are obtained combining $\mathrm{Al}$ with other constituents like $\mathrm{Cu}, \mathrm{Zn}, \mathrm{Mg}$, $\mathrm{Si}$ and $\mathrm{Mn}$, and are characterized by low density, high ductility and good resistance to corrosion.

Mechanical components are mostly designed to operate within the elastic field. However, in some specific sectors, e.g. crashing and impacts, it is important to also know the plastic behaviour of materials. Yielding criteria cannot be used for predicting failure, and therefore other approaches taking into account also the plastic deformations must be used to describe the fracture locus (FL) of materials.

The present work is aimed to present an experimental and numerical characterization of AlSil0Mg alloy. Several tensile tests were carried out on samples having different geometries, namely different stress states. The results of the tests were used to identify the constitutive law of the material and to calibrate a ductile damage model capable to predict the failure also in presence of high plastic deformations.

The stress state inside the material can be described by means of the stress tensor. While for the simplest model, the Maximum Strain one, the material fails when the accumulated equivalent plastic strain reaches a critical value, other more advanced formulations related the ductile damage to the stress state. Specifically, one of the most used parameter for describing the stress state is the triaxiality, namely the first stress invariant normalized by the von Mises equivalent stress. It decreases the failure strain of ductile materials exponentially (Rice and Tracey [1], Mackenzie et al. [2], Johnson and Cook [3]). Concli and Maccioni [4] calibrated the fracture locus of a weathering steel (CORTEN) using the Johnson-Cook model. Concli and Gilioli used the fracture locus of an A357 Aluminum alloy [5], [6] and of an 18-Ni300 steel [7] to assess the failure mechanisms of reticular structures produced via Selective Laser Melting (SLM). Bao and Wierzbicki [8] and Wierzbicki et al. [9] demonstrated that the different ranges of triaxiality are associated to different failure mechanisms. Barsoum et al. [10], Graham et al. [11] calibrated ductile damages models for different levels of triaxiality. Papasidero et al. [12] performed non-proportional load tests concluding that a linear model is not suitable for the description of these load conditions. Cortese et al. [13], [14] proposed a non-linear model that considers non proportional loads. 
The Lode parameter, alias the third deviatoric invariant exploited with the Lode angle, has shown evidence in the mechanisms of ductile fracture (Mae et al. [15], Xue et al. [16], Ghajar et al. [17]).

In this paper, the Rice and Tracey was calibrated for an AlSi10 alloy.

\section{MATERIAL AND METHODS}

Experimental tests were performed on an MTS Criterion 45 machine owned by the Free University of Bolzano/Bozen. Force-displacement curves were obtained with tensile tests on three different geometries. A first sample has a smooth cylindrical geometry, while the others show notches to induce different stress states in the material (Fig. 1). Tests were performed with a crosshead displacement velocity of $0.1 \mathrm{~m} / \mathrm{min}$ to avoid excessive heat generation that can affect the mechanical properties. Tests were run up to the break of the samples.
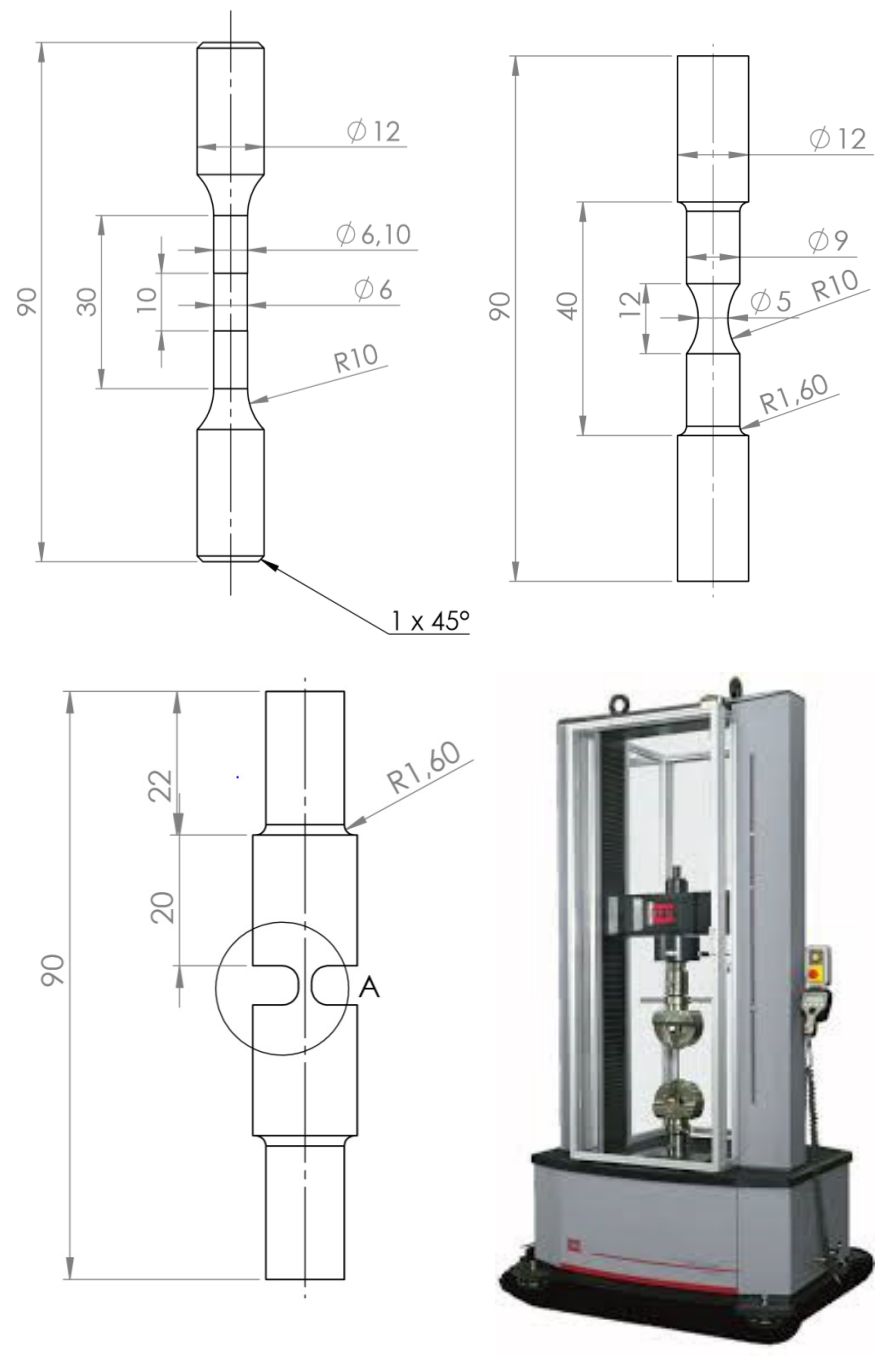

Figure 1: Technical specifications of the tested specimens and testing machine. 
The calibration of the constitutive law $\sigma-\varepsilon$ was done by means of an experimentalnumerical procedure in which the experimental configurations were reproduced in a the opensource FE software Salome Meca/Code Aster. The constitutive law was found iteratively comparing the results of the FE simulations in terms of force-displacement (F-s) with those measured experimentally during the tensile tests. The calibration procedure bases on the representation of the constitutive law by means of the Voce equation. This is a flexible parametric equation that reduces the number of parameters to be calibrated to 4

$$
\sigma_{v o c e}=A+B \cdot\left(1-e^{-C \cdot \varepsilon_{p l}}\right)+D \cdot \varepsilon_{p l},
$$

where $A$ is the yielding stress (directly obtained from the elaboration of the measured data) and $B, C$ and $D$ are the linear coefficient, the exponential coefficient and saturation coefficient to be tuned. The iterative procedure led to the curve shown is Fig. 2. The calibrated parameters are shown in Table 1.

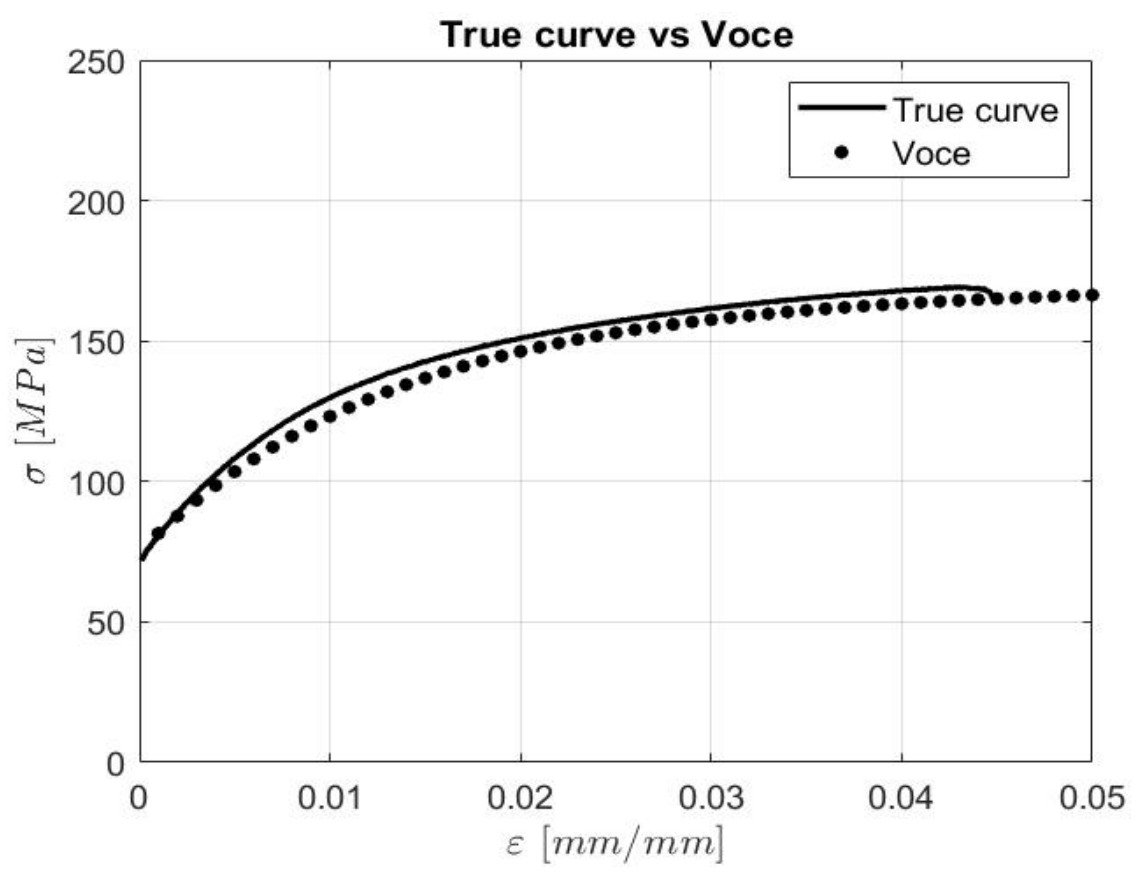

Figure 2: True stress-strain vs Voce calibrated curve.

Table 1: Voce parameters.

\begin{tabular}{|c|c|c|c|}
\hline $\mathrm{C}_{1}(\mathrm{MPa})$ & $\mathrm{C}_{2}(\mathrm{MPa})$ & $\mathrm{C}_{3}(-)$ & $\mathrm{C}_{4}(\mathrm{MPa})$ \\
\hline 75 & 90 & 75 & 70 \\
\hline
\end{tabular}

As previously mentioned, over the years different mathematical formulations have been proposed for describing the fracture locus. There isn't a formulation that can be considered the most effective in predicting the failure. The selection of the proper one is strongly 
dependent from the ductility of the material considered. For material having a low ductility, in fact, the maximum strain model is often the best performing.

The model proposed by Rice and Tracey [1] considers a monotonic decreasing relation between the equivalent plastic strain at failure $\left(\varepsilon_{\text {peeq }}\right)$ and the triaxiality $(t)$.

$$
\varepsilon_{\text {peeq }}=\left[D_{1}+D_{2} \cdot \exp \left(D_{3} \cdot t\right)\right],
$$

where the triaxiality $t$ is defined as the ratio between the mean stress and the equivalent stress. $T$.

Johnson and Cook [3] extended this model including the strain rate $\dot{\varepsilon_{p}}$ and the temperature

$$
\varepsilon_{f}=\left[D_{1}+D_{2} \cdot \exp \left(D_{3} \cdot t\right)\right] \cdot\left[1+D_{4} \cdot \ln \left(\dot{\varepsilon_{p}}\right)\right] \cdot\left[1+D_{5} \cdot T\right],
$$

where $D_{1}, D_{2}, D_{3}, D_{4}$ and $D_{5}$ are constants to be calibrated.

Further studies by Bao and Wierzbicki [8], Wierzbicki et al. [9] and Gilioli et al. [18] showed that different levels of triaxiality are associated to different failure mechanisms. In particular, failure is due to shearing for negative values of triaxiality and to void formation mechanism for high positive values of triaxiality. In between, fracture originates due to a combination of the previous mechanisms (Fig. 3).

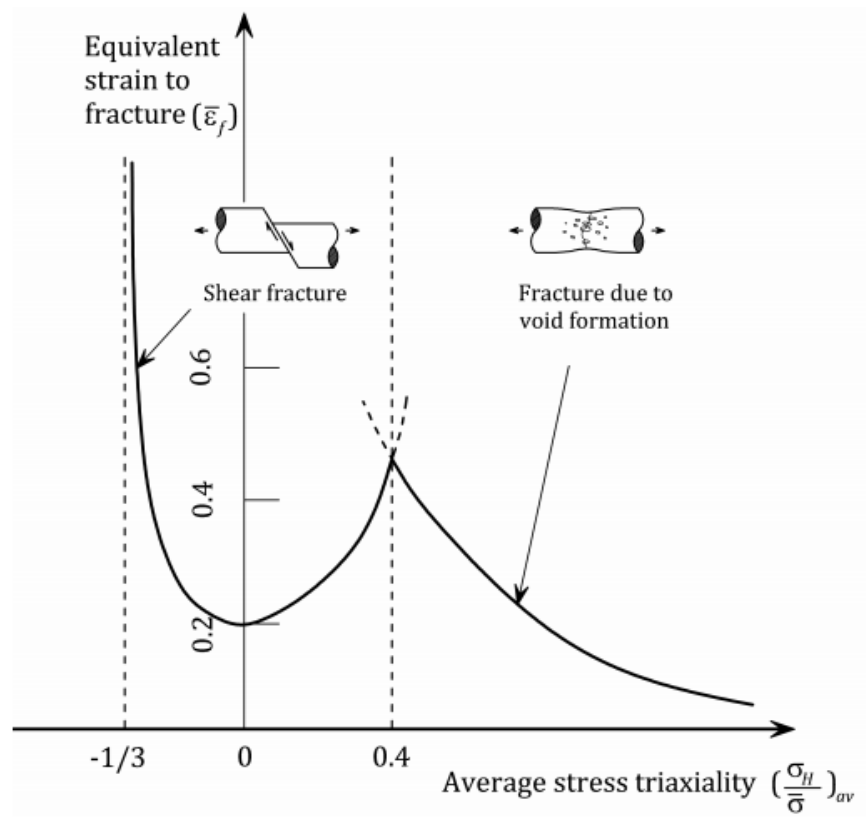

Figure 3: Influence of stress triaxiality on the equivalent strain to fracture [4].

Xue and Wierzbicki [19] proposed a damage model in which fracture occurs when a function depending on the equivalent plastic strain, the triaxiality and the Lode parameter becomes equal to one

$$
\int_{0}^{\varepsilon_{f}} \frac{d \varepsilon}{F(t, \xi)}=1
$$

where $\xi$ is the Lode parameter defined as 


$$
\xi=\frac{27}{2} \frac{J_{3}}{\sigma_{v M}^{3}},
$$

where $J_{3}$ is the third invariant of the deviatoric stress tensor and $\sigma_{v M}$ is the equivalent Von Mises stress.

This research focuses on high levels of triaxiality. The corresponding fracture locus is therefore calibrated according to the Rice and Tracey model (decreasing exponential function).

\section{RESULTS}

All the tested configurations were reproduced numerically with the open-source software Salome_Meca/Code_Aster [20]. Two specimens were modelled taking advantage of their axis-symmetry with $2 \mathrm{D}$ elements while the third was modelled with $3 \mathrm{D}$ elements. The simulations are intrinsically non-linear due to the plastic deformations. The displacement corresponding experimentally to the failure was imposed in the FE model: the equivalent plastic strain and the triaxiality were extracted from the numerical simulations (Figs 4-6).
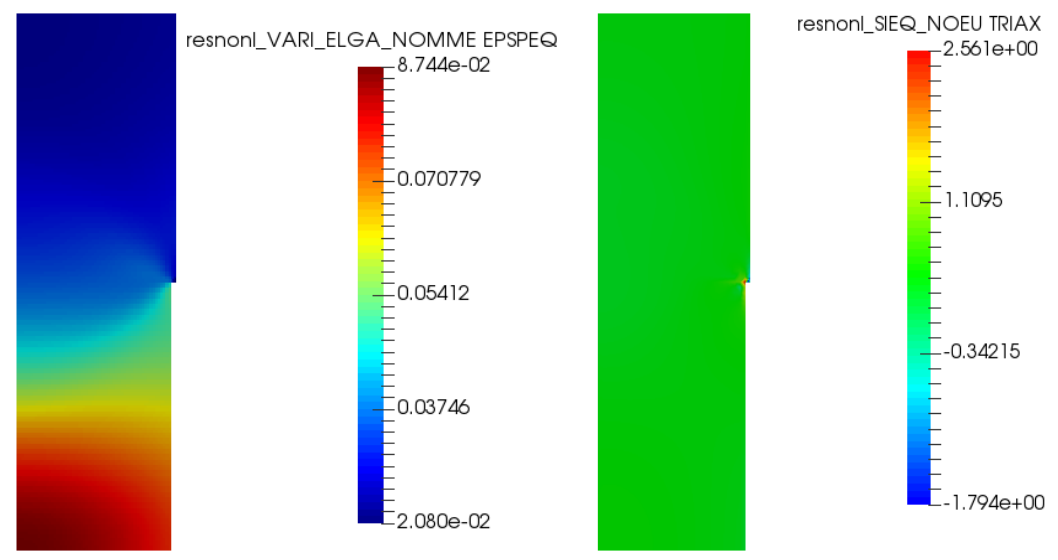

Figure 4: Equivalent plastic strain at fracture and triaxiality, sample \#1.
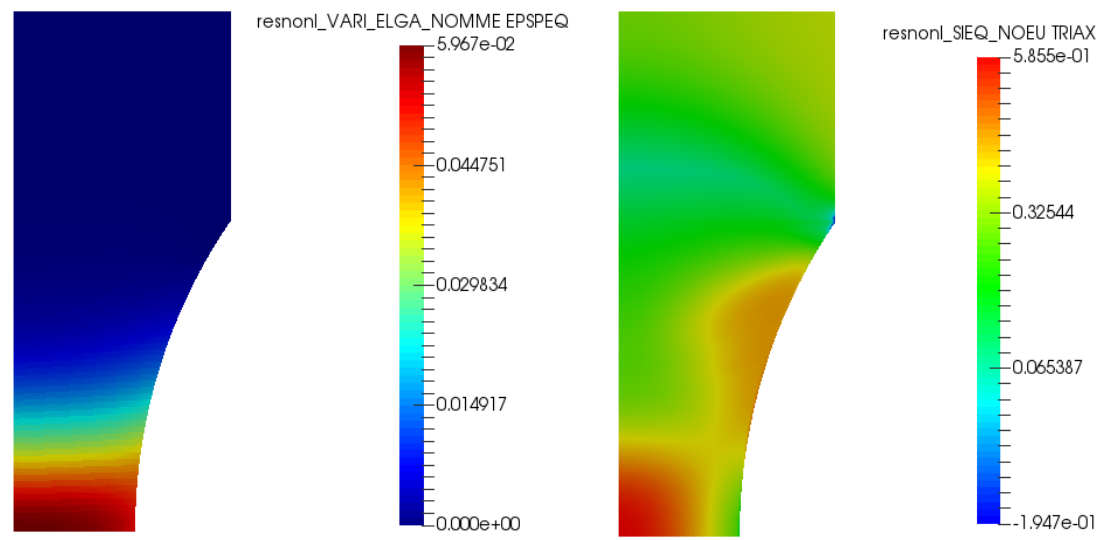

Figure 5: Equivalent plastic strain at fracture and triaxiality, sample \#2. 


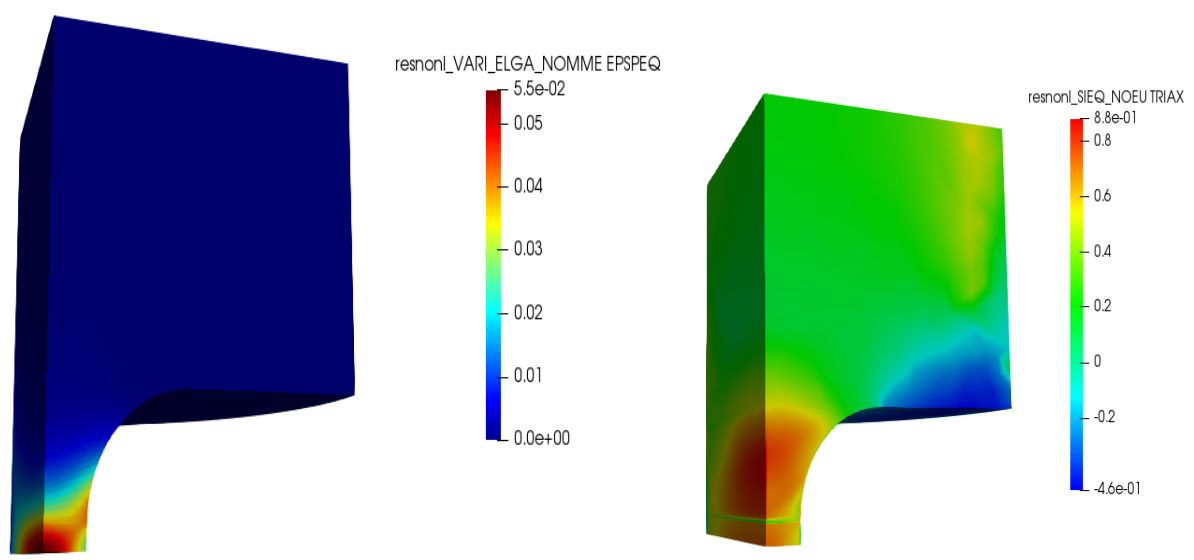

Figure 6: Equivalent plastic strain at fracture and triaxiality, sample \#3.

The data extracted from the numerical analysis, namely the combination of equivalent plastic strain and triaxiality used to calibrate the fracture locus, are summarized in Table 2.

The calibrated fracture locus results from the interpolation of the three point with the leastsquares method and is shown in Fig. 7.

Table 2: Parameters for the calibration of the fracture locus.

\begin{tabular}{|c|c|c|c|}
\hline Specimen & $\varepsilon_{\text {peeq }}$ & $t$ & $\xi$ \\
\hline$\# 1$ & 0.087 & 0.39 & 1 \\
\hline$\# 2$ & 0.059 & 0.59 & 1 \\
\hline$\# 3$ & 0.055 & 0.70 & 0 \\
\hline
\end{tabular}

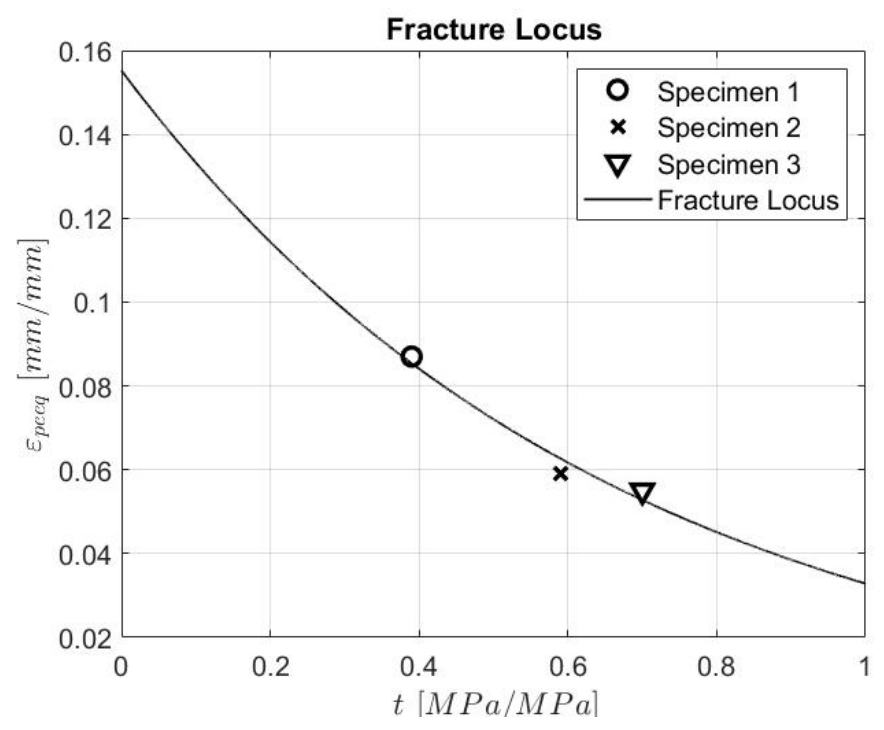

Figure 7: Fracture locus of the considered material. 


\section{CONCLUSIONS}

In this paper, by means of a procedure that relies on both experimental tests and numerical analysis, the constitutive law of an AlSi10 alloy was fine-tuned.

Moreover, the Rice and Tracey ductile damage model has been calibrated. The effects of the strain rate and of the temperature have been neglected but will be included in future studies.

Further experimental measurements on different geometries are planned to also include the effect of the Lode parameter in the calibration of the fracture locus.

\section{REFERENCES}

[1] Rice, J.R. \& Tracey, D.M., On the ductile enlagrgement of voids in triaxial stress fields. J. Mech. Phys. Solids, 17, p. 201, 1969.

[2] Mackenzie, A.C., Hancock, J.W. \& Brown, D.K., On the influence of state of stress on ductile failure initiation in high strength steels. Eng. Fract. Mech., 9, pp. 167-188, 1977.

[3] Johnson, G.R. \& Cook, W.H., Fracture characteristics of three metals subjected to various strains, strain rates, temperatures and pressures. Eng. Fract. Mech., 21(1), pp. 31-48, 1985.

[4] Concli, F. \& Maccioni, L., Experimental-numerical calibration of the fracture locus of a weathering steel. WIT Transactions on Engineering Sciences, WIT Press: Southampton and Boston, pp. 219-227, 2019.

[5] Concli, F. \& Gilioli, A., Numerical and experimental assessment of the static behavior of 3D printed reticular Al structures produced by selective laser melting: Progressive damage and failure. Procedia Struct. Integr., 12, pp. 204-212, 2018.

[6] Concli, F., Gilioli, A. \& Nalli, F., Experimental-numerical assessment of ductile failure of additive manufacturing selective laser melting reticular structures made of Al A357. Proc. Inst. Mech. Eng. Part C J. Mech. Eng. Sci., 095440621983233, 2019.

[7] Concli, F. \& Gilioli, A., Numerical and experimental assessment of the mechanical properties of 3D printed 18 -Ni300 steel trabecular structures produced by selective laser melting: A lean design approach. Virtual Phys. Prototyp., 2019.

[8] Bao, Y. \& Wierzbicki, T., On fracture locus in the equivalent strain and stress triaxiality space. Int. J. Mech. Sci., 46(1), pp. 81-98, 2004.

[9] Wierzbicki, T., Bao, Y., Lee, Y.W. \& Bai, Y., Calibration and evaluation of seven fracture models. Int. J. Mech. Sci., 47(4-5), pp. 719-743, 2005.

[10] Barsoum, I., Faleskog, J. \& Pingle, S., The effect of stress state on ductility in the moderate stress triaxiality regime of medium and high strength steels. Int. J. Mech. Sci., 65, pp. 203-212, 2012.

[11] Graham, S., Zhang, T., Gao, X. \& Hayden, M., Development of a combined tensiontorsion experiment for calibration of ductile fracture models under conditions of low triaxiality. Int. J. Mech. Sci., 54, pp. 172-181, 2012.

[12] Papasidero, J., Doquet, V. \& Mohr, D., Determination of the effect of stress state on the onset of ductile fracture through tension-torsion experiments. Exp. Mech., 54, pp. 137-151, 2014.

[13] Cortese, L., Nalli, F. \& Rossi, M., A nonlinear model for ductile damage accumulation under multiaxial non-proportional loading conditions. Int. J. Plast., 85, pp. 77-92, 2016.

[14] Cortese, L., Coppola, T., Campanelli, F., Campana, F. \& Sasso, M., Prediction of ductile failure in materials for onshore and offshore pipeline applications. Int. J. Damage Mech., 23(1), pp. 104-123, 2014. 
[15] Mae, H., Teng, X., Bai, Y. \& Wierzbicki, T., Calibration of ductile fracture properties of a cast aluminum alloy. Mater. Sci. Eng. A, 459(1), pp. 156-166, 2007.

[16] Xue, Z., Pontin, M., Zok, F.W. \& Hutchinson, J.W., Calibration procedures for a computational model of ductile fracture. Eng. Fract. Mech., 77, pp. 492-509, 2010.

[17] Ghajar, R., Mirone, G. \& Keshavarz, A., Sensitivity analysis on triaxiality factor and lode angle in ductile fracture. J. Mech., 29, pp. 177-184, 2013.

[18] Gilioli, A., Manes, A., Giglio, M. \& Wierzbicki, T., Predicting ballistic impact failure of aluminium 6061-T6 with the rate-independent Bao-Wierzbicki fracture model. Int. J. Impact Eng., 76, pp. 207-220, 2015.

[19] Xue, L. \& Wierzbicki, T., Ductile fracture characterization of aluminum alloy 2024t351 using damage plasticity theory. Int. J. Appl. Mech., 1(2), pp. 267-304, 2009.

[20] Code-Aster. 